\title{
A Vision Becomes Reality
}

\author{
by Pamela Doyle
}

\section{7}

he automation of the fiftyeight community college libraries in North Carolina has been a long, slow process, but now a vision of a statewide library automation system - begun in 1984 - may soon become a reality. Thirty-six of the colleges will join the Dynix Automation Center (DAC) this fiscal year. Over the next three to five years, as the DAC is moved from a host-based to a client/ server environment, it is anticipated that more of the colleges will join this cooperative.

\section{Background of Community College Libraries}

Since the establishment of the community college system in 1963, the sharing of resources, ideas, knowledge, and cooperation has been a general theme of library services. In the days when community colleges were first getting started, there were few professional librarians to build library collections and define policies for library services. When librarians began submitting book orders to Library Services in Raleigh for centralized acquisitions and cataloging, copies of each title were ordered for all the libraries, the theory being that if it was needed by one college for a basic library collecffon, it must be needed by all. As more professional librarians were employed, fewer orders were duplicated and individual library collections began to reflect the curricula taught by the college.

The sense of cooperation was inherent in the life of the library. Librarians employed by newly established commu- nity colleges were often selected from the staffs of other community colleges, and those coming from other types of libraries were encouraged to visit neighboring community colleges libraries and to seek assistance from the librarian to understand the policies and procedures that must be followed. Because community colleges were a new educational entity in North Carolina, Library Schools were not prepared to teach the educational philosophy of the community college or to emphasize collection development specialities of the technical and vocational education programs that were offered there. Education for the early community college librarians came through trial and error. Education for the librarians who followed came from fellow community college librarians. Thus, community college librarians in North Carolina have a very real sense of cooperation and understanding of their common needs.

\section{Early Resource Sharing Efforts}

First efforts to automate the community college libraries according to some library standard came in 1984. Some libraries had begun retrospective conversion projects as early as 1979 in anticipation of closing their card catalogs and replacing them with Compute Output Microform (COM) catalogs. In 1983, several libraries joined a retrospective conversion consortium and contracted with General Research Corporation to convert to COM catalogs. By the mid 1980 s, approximately one-third of the fifty-eight libraries were involved in conversions.

During the same period, the Depart- ment of Community College (DCC) administration made the decision to convert all college financial reporting to a single computerized hardware platform. The Request for Proposals (RFP) included requirements for a library component, but the specifications were minimal and very general, totalling less than one page in length. In 1984, the DCC administration accepted the recommendation to contract for the installation of Prime computers systemwide and to license several administrative software packages for statewide use. Responses to the RFP did not include library software.

In the spring of 1984, the Automation Committee of the North Carolina Community College Learning Resources Association (NCCCLRA) began writing specifications for a library software package that would meet the needs of the community college libraries. That fall, NCCCLRA presented to its membership an extensive 32-page listing of library software specifications that was used to critique library software packages exhibited at the Institutional Information Processing Systems (IIPS) conference that October. Among three vendors advertising library software for Prime computers, only one, Dynix, had a library software product that appeared to meet the specifications.

Over the next two years, efforts were made by NCCCLRA and Library Services personnel to gain support from the DCC administration to purchase the Dynix Library Software Package for statewide use. After numerous meetings and demonstrations, in 1987 the decision was made not to pursue a statewide licensing 
of the Dynix software but to place Dynix software on a State Convenience Contract for any community college to purchase, if it desired.

Many factors contributed to the vision of a standard statewide library system. Community colleges were using the Prime computer for most local automation needs other than instructional. The community college system was implementing a new community college network, CCNET, using the LINCNet telecommunications facilities of the Educational Computing Services, University of North Carolina. By this time, 50 percent of the libraries had completed or were involved in retrospective conversion projects. They were ready for a better alternative to the card catalog than the COM catalog was offering.

\section{Software and Hardware Issues}

Over the next seven years, library automation in the community college system became a hodgepodge of library software systems. Dynix emerged as the library automation leader with twentythree systems running on the Prime hardware platform and four running on microcomputer hardware. Highland Library Systems was also a major player, with thirteen microcomputer-based systems. Other vendors included DataTrak,

The following advantages of becoming a part of the DAC were presented as part of the Dynix Automation Center Executive Summary:

1. The DAC will be an integrated, networked library software package in which any library user can have access to all the library holdings in the community colleges system. Sharing of library resources will be enhanced.

2. There will be one single library system to maintain rather than 58 systems.

3. ALS will provide the System Administrators (SAs) needed to man the DAC. Local Prime SAs will be required to maintain only the local network connections.

4. Library Services at the Department of Community Colleges will be uploading the OCLC bibliographic/cataloging records directly into the DAC, eliminating local uploading.

5. Migration to the DAC will resolve the local issue of migrating the library to Unix.

6. The DAC will provide an inexpensive way for non-automated libraries to automate.

7. Because of the way we are specifying how the colleges will be network compatible, they will also be Internet compatible.
Winnebego, DOBIS, Nonesuch, and Follett. As technological developments evolved in community college networking, the use of multiple library software packages offered little hope that library automation would become a single coherent bibliographic utility accessible by all community college libraries.

The original vision of having one standard library software package in use at all fifty-eight community college libraries would have enabled NCCCLRA and DCC to pursue developing a transparent meshing of the library collections within a given region or even on a statewide basis. The Triangle Research Libraries Network had successfully meshed the massive research collections of Duke University, North Carolina State University, and the University of North Carolina at Chapel Hill. To library programming novices, this seemed a very plausible and worthwhile project for the community colleges.

The image of a community college libraries union catalog and library system, however, was not to become a reality. Instead, community college libraries used telecommunications resources available to them and began networking on a one-to-one basis. Libraries with the Dynix Library software installed on Prime computers shared login IDs and passwords and began using the online public access catalogs of other colleges for collection development, local cataloging, and creation of bibliographies. When new curricula were added to a college, librarians checked the collections of other colleges offering the same or similiar curricula. Dynix/Prime sites and one Highland site were the only library catalogs available online.

As library personnel became more accustomed to venturing into other library systems, access was broadened to include non-community college library collections in North Carolina and some libraries available via the Internet. DCC Information Services personnel, in cooperation with ECS personnel, set up the CC.LIBNET, menus of libraries and information resources available through the Prime computer and LINCNet. These menusincluded access to the North Carolina Information Network, which is administered by the Division of State Library, Department of Cultural Resources. Libraries gained access to DIALOG, Library of Congress, MELVYL, CARL, ERIC, NASA, and other databases and library services.
Even though the vision of a community college library network was not what had originally been hoped for, a library network was evolving and libraries were becoming more involved in local implementation of technology and telecommunications. Libraries often were the force requiring the colleges to move into untried technologies. They began expanding the networking and resource sharing concepts by developing local wide area networks with multitype libraries. They began marketing community colleges through library services to other libraries. Beaufort County Community College implemented the Down East Area Network (DEAN) with public high schools in rural areas of eastern North Carolina. Pitt Community College began the Pitt Education Program (PEP) with public middle and high schools. Wayne Community College coordinated the development of the Wayne Information Network (WIN), a more comprehensive multitype library network, which included public schools, a military library, a four-year academic library, hospital libraries, private school libraries, the public libraries, and others.

\section{Libraries and Technology}

In the ten years since the first thrust for a standard statewide library system, Iibraries had become significant players in the technological development at the community colleges. The North Carolina Information Highway, the Internet, and the National Information Infrastructure made libraries even more aware of how far some had advanced with automation, while others still had not begun a retrospective conversion process in preparation for library automation. With each advance in technology, bridging the gap between libraries with automation and those without became more difficult. Addressing library issues involving library automation was an issue within itself, because there were so many different systems. The absence of one standard library software system in place or planned for meant that the impact on all library systems had to be considered when decisions were made.

\section{Acquisitions and the DAC}

In 1993, the DCC administration decided to automate the centralized acquisitions functions of Library Services. An acquisitions committee began revising the library specifications written in 1984 in anticipation of issuing a Request For Bids. The committee decided to include specifications for all aspects of library automation. There was still a strong de- 
sire to have a single library software package in use statewide. As work of the acquisitions committee progressed, its mission broadened to address technology issues that were arising and would impact the libraries.

The first of these issues involved hardware. After many years with Prime computers, the community colleges system made the decision to migrate administrative software packages to three different hardware platforms - IBM Risk 6000 , Sun Spark Station, and Bull Intel SCO Unix. The Dynix software also resided on the administrative Prime computer, so migration of the Dynix system to another platform and the associated costs became an issue that the committee needed to address.

Secondly, the North Carolina Information Highway was coming to life in several of the colleges. With this new life came a desire to put into place as much of the hardware and telecommunications connections as possible to encourage the colleges to become involved in the NCIH.

Dynix, now known as Ameritech Library Services (ALS), received many calls concerning hardware that could be used with its software, the costs of migrating the Dynix/Prime sites to the new hardware, and the time frames for the migrations. In July 1994, ALS representatives met with DCC adminstrators and Dynix clients and proposed the implementation of a Dynix Automation Center (DAC) as an answer to all the issues. The cost of the DAC was based on a minimum number of user fees and annual fees for use of some software modules. ALS proposed providing the hardware and the personnel to run the DAC within the new network environment, if DCC would provide space for the hardware and office space for the DAC System Administrator. The proposal included migration and conversion costs for all community colleges, not just the current Dynix clients.

The DAC will be a centralized library system, housed in Raleigh and maintained by an ALS System Administrator. User fees include use of the Cataloging, Circulation, Public Access, Community Resources or Reserve Book Room, and Gateway modules. Other modules available for an additional fee include Serials, Media Scheduling, and Vista (a software that enables library users to access a variety of databases from many vendors). Because DCC's original intent was to have an automated acquisitions system, it will pay ongoing costs for the Acquisitions module for the colleges.
Through the use of the Gateway module, many of the libraries and information resources currently accessed through CC.LIBNET will still be available both to community college students and individuals using services through local wide area networks, such as DEAN, PEP, and WIN. The DAC will be accessible via existing networks, the $\mathrm{NCIH}$, or the Internet.

The major adjustment for library patrons and personnel will come in having a union catalog with merged bibliographic records. Theoretically, there will be one bibliographic record for each title, with all holdings attached to that record. Colleges will have some options in allowing local patrons to see holdings at other colleges. With the DAC, there is increased potential for more statewide cooperations in such areas as statewide licensing of information products and databases and improved statewide discounts for library purchases.

\section{Planning for the DAC}

The NC Community College Dynix Users Group liked the proposal and requested that the DCC investigate the feasibility of establishing the DAC and that it pursue, through required state government procedures, signing a contract with ALS for a DAC. Since the DAC had the potential to become a statewide library system, an awareness campaign was initiated. An executive summary of the DAC proposal and associated costs were distributed electronically to the college presidents, library directors, and Prime system administrators. In Novem- ber, regional meetings were held. ALS representatives demonstrated the features of the Dynix software and discussed its use in the proposed DAC environment. DCC representatives talked about the procedures that would be followed to make the DAC a reality and addressed its operation in the networked environment. DAC sessions were scheduled at conferences and seminars to respond to questions and resolve issues that had arisen.

Following many months of presentations and education to potential system users, a letter was sent to each college president outlining local costs. As part of that letter, each president was asked to indicate a commitment to the DAC. Thirty-six of the fifty-eight colleges returned letters of commitment to the DAC. Having secured the minimum number of users required in the DAC proposal, the DCC administration began the process of obtaining approval for the DAC through the state government agencies that must review telecommunications/networking proposals.

\section{Preparing for the DAC}

Even though the DAC had not received official approval, the DCC and the Dynix Users Group (now expanded to include all the DAC participants) began organizing into committees to address the various aspects of systemwide cooperation that the DAC required. In March, DCC and ALS personnel met with library and system administration personnel from each of the DAC colleges. Staff from the DCC Information Ser-

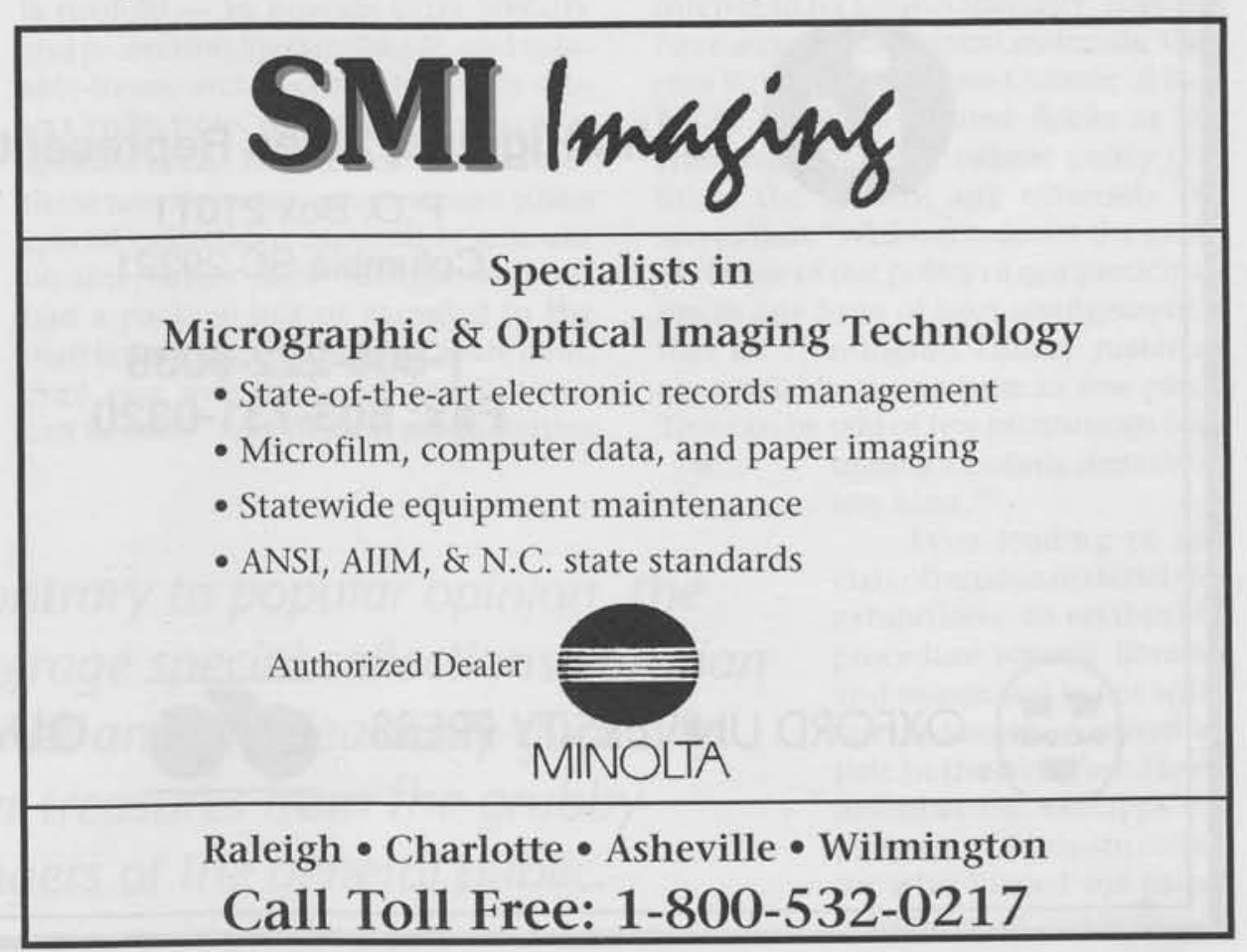


vices outlined the network configurations proposed for the DAC and discussed hardware requirements. An ALS team of representatives gave an overview of the implementation and migration project; presented concepts to be considered when making decisions about mapping, indexing, and displays within the cooperative environment; and outlined the migration procedures and issues that needed to be considered.

Four committees were charged with addressing codes, indexing, display and mapping, and interlibrary loan for the DAC colleges. Each committee chair submitted draft and final reports, which were incorporated into installation manuals.

The committees have completed their work. Individual colleges will complete the pre-installation information, adapting or accepting the committee information as needed and providing other information specific to their library. The chairman of the Dynix Users Group, the chairmen of the four committees, the DCC Coordinator of Library Technical Assistance, and the DAC System Administrator will continue to serve on a DAC Steering Committee. As the need arises, other committees will be appointed to address specific needs. The original Acquisitions Committee that began the process of automating acquisitions will be replaced by another committee that will make decisions about setting up the DAC acquisitions module to best meet the needs of the colleges and DCC.

\section{National Perspective}

Currently, ALS has three other DACs in operation. The first began operation in Indianapolis, and now has two school districts and one public library (twelve sites). There are two other multitype DACs in Chicago and Michigan.

ALS sees a government trend toward out-sourcing. An automation center eliminates some of the political and governing issues that can arise with a consortium. Because equipment is leased, there are fewer worries about replacing obsolete CPUs. Costs are put in an operations budget rather than in capital outlays. Participants have the benefits of resource sharing without having to agree on as many issues as they would in a consortium arrangement. The fact that the participants in the North Carolina DAC are already part of the same governing structure made the initial establishment easier still.

\section{Future Concerns}

On June 29, 1995, the Dynix Automa- tion Center contract with Ameritech Library Services was signed by the President of the North Carolina Community College System, almost exactly one year after the DAC proposal had been presented for the first time. There is still much to do. Guidelines for sharing bibliographic and serials databases must be addressed. Training for all modules must be carried out, with classes to be offered as colleges begin migrating in October. Equipment that meets all functionality tests in the ANCHORNet (A North Carolina Information Highway On Ramp) and DAC environment must be installed at each college. Some colleges that are converting from other library software systems must re-barcode their collections. Current procedures must be studied and revised for efficiency in the new environment.

Cooperation among the colleges will be the key to the success of the DAC, just as it has been the key to the success community college libraries have experienced throughout their thirty-year history. Training workshops, migration meetings, and pre-installation sessions will be blended with barcoding parties to meet deadlines and to get all libraries operating on the DAC - a vision of cooperation to make another vision become a reality.

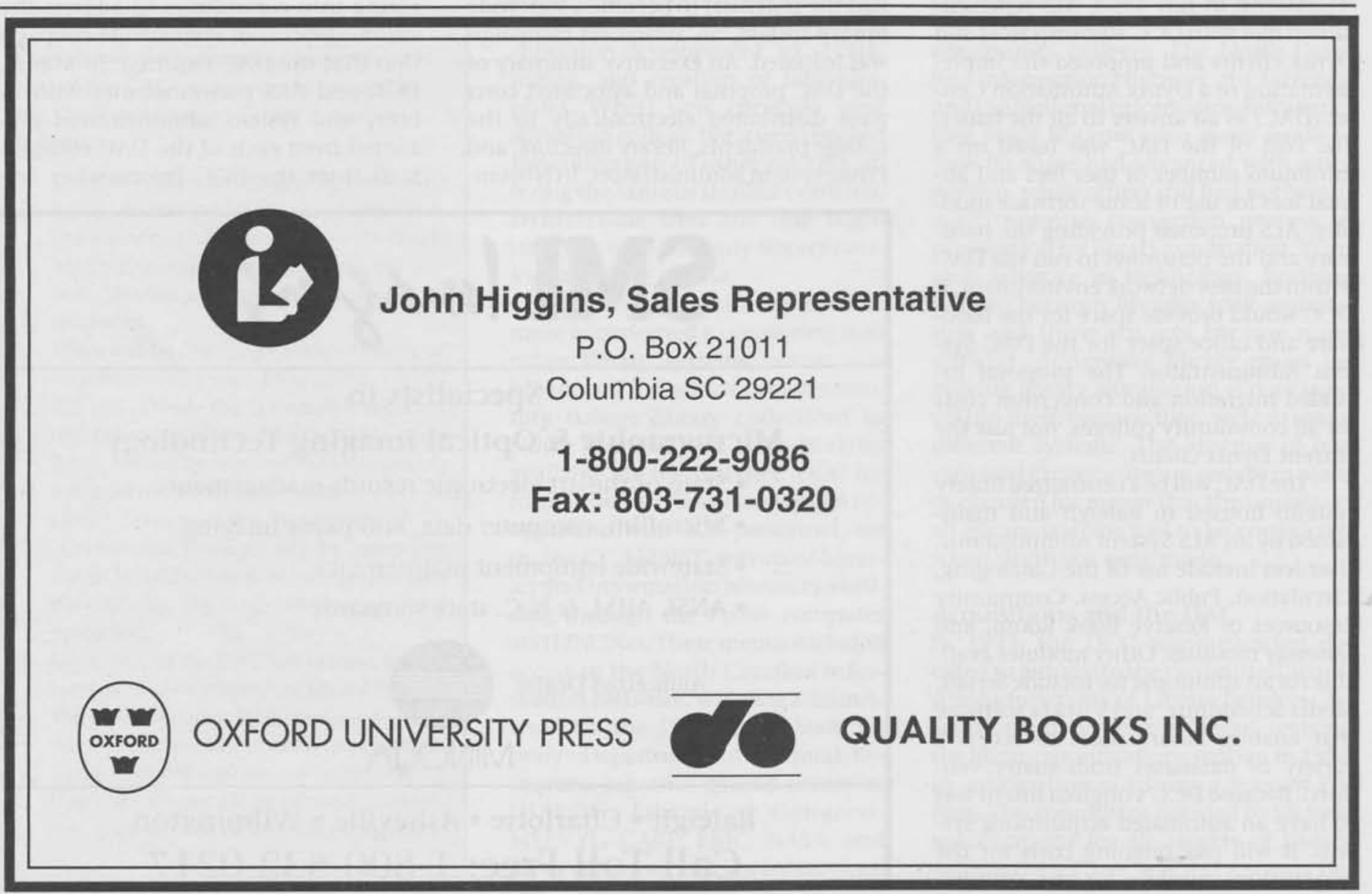

